Article

\title{
Structure-Activity Relationship of Oligomeric Flavan-3-ols: Importance of the Upper-Unit B-ring Hydroxyl Groups in the Dimeric Structure for Strong Activities
}

Yoshitomo Hamada ${ }^{1}$, Syota Takano ${ }^{2}$, Yoshihiro Ayano ${ }^{1}$, Masahiro Tokunaga ${ }^{2}$, Takahiro Koashi ${ }^{1}$, Syuhei Okamoto ${ }^{1}$, Syoma Doi ${ }^{1}$, Masahiko Ishida ${ }^{2}$, Takashi Kawasaki $^{3}$, Masahiro Hamada ${ }^{4}$, Noriyuki Nakajima ${ }^{4, *}$ and Akiko Saito ${ }^{1,2, *}$

1 Graduate School of Engineering, Osaka Electro-Communication University (OECU), 18-8 Hatsu-cho, Neyagawa-shi, Osaka 572-8530, Japan; E-Mails: me14a007@oecu.jp (Y.H.); me14a001@oecu.jp (Y.A.); me14a005@oecu.jp (T.K.); me12a003@oecu.jp (S.O.); me12a008@oecu.jp (S.D.)

2 Faculty of Engineering, Osaka Electro-Communication University (OECU), 18-8 Hatsu-cho, Neyagawa-shi, Osaka 572-8530, Japan; E-Mails: eg10a032@osakac.info (S.T.); eu11a066@oecu.jp (M.T.); eg10a006@osakac.info (M.I.)

3 Department of Pharmaceutical Sciences, Ritsumeikan University, 1-1-1 Nojihigashi, Kusatsu, Shiga 525-8577, Japan; E-Mail: kawa0227@fc.ritsumei.ac.jp

4 Biotechnology Research Center and Department of Biotechnology, Toyama Prefectural University, 5180, Kurokawa, Imizu, Toyama 939-0398, Japan; E-Mail: hamada@pu-toyama.ac.jp

* Authors to whom correspondence should be addressed; E-Mails: nori@pu-toyama.ac.jp (N.N.); a-saito@isc.osakac.ac.jp (A.S.); Tel.: +81-766-56-7500 (N.N.); +81-72-824-1131 (A.S.); Fax: +81-766-56-2498 (N.N.); +81-72-824-0014 (A.S.).

Academic Editor: Thomas J. Schmidt

Received: 30 June 2015 / Accepted: 7 October 2015 / Published: 16 October 2015

\begin{abstract}
Proanthocyanidins, which are composed of oligomeric flavan-3-ol units, are contained in various foodstuffs (e.g., fruits, vegetables, and drinks) and are strongly biologically active compounds. We investigated which element of the proanthocyanidin structure is primarily responsible for this functionality. In this study, we elucidate the importance of the upper-unit of 4-8 condensed dimeric flavan-3-ols for antimicrobial activity against Saccharomyces cerevisiae (S. cerevisiae) and cervical epithelioid carcinoma cell line HeLa S3 proliferation inhibitory activity. To clarify the important constituent unit of proanthocyanidin, we synthesized four dimeric compounds, (-)-epigallocatechin-[4,8]-(+)-catechin, (-)-epigallocatechin-[4,8]-(-)-
\end{abstract}


epigallocatechin, (-)-epigallocatechin-[4,8]-(-)-epigallocatechin-3-O-gallate, and (+)-catechin[4,8]-(-)-epigallocatechin and performed structure-activity relationship (SAR) studies. In addition to antimicrobial activity against $S$. cerevisiae and proliferation inhibitory activity on HeLa S3 cells, the correlation of 2,2-diphenyl-1-picrylhydrazyl radical scavenging activity with the number of phenolic hydroxyl groups was low. On the basis of the results of our SAR studies, we concluded that B-ring hydroxyl groups of the upper-unit of the dimer are crucially important for strong and effective activity.

Keywords: condensed tannins; oligomeric flavonoid; synthesis; DPPH radical scavenging activity; antimicrobial activity; cancer cell proliferation inhibitory activity

\section{Introduction}

Currently, there is great interest in the strong biological activity of compounds commonly found in some foods. Such compounds have been considered safe functional compounds. Polyphenols are found in various plants such as vegetables and fruits and are consumed regularly [1,2]. Among polyphenol compounds, proanthocyanidins such as oligomeric flavan-3-ols and condensed tannins are known to be strongly bioactive compounds. It is widely believed that proanthocyanidins have a beneficial impact on health; therefore, they are included in various health foods, and scientific investigations of proanthocyanidins are becoming increasingly important. However, the structure-activity relationship (SAR) of proanthocyanidins is not well understood because, in many cases, they are obtained as mixtures of various analogues. Thus, purification of each compound is difficult. Therefore, synthesis is considered the most suitable method for clarifying the SAR of proanthocyanidins. Following contribution by Kozukowski et al. [3-5], many studies on proanthocyanidin synthesis and their biological properties were demonstrated [6-14].

We have also reported a simple, versatile, stereoselective and length controlled synthetic method for various procyanidins, a member of the proanthocyanidin class, which have two hydroxyl groups on the B-ring. We demonstrated that galloyl modification of the hydroxyl groups of flavan-3-ols enhanced their biological activities [15-18]. We further reported the synthesis of semi-acetylated analogues 1-3 of procyanidin B1, a dimeric flavan-3-ol, and discussed their inhibitory activities against HeLa S3 cell proliferation (Figure 1). The lower-unit acetylated procyanidin B1 (2) strongly inhibited proliferation of HeLa S3 cells, whereas procyanidin B1 (1) and the upper-unit acetylated analog 3 showed no inhibitory activity [19]. These results indicated that the upper-unit of dimeric flavan-3-ol is critical for biological activity. More recently, we elucidated that there is poor correlation between the inhibitory activity of HeLa S3 cell proliferation and 2,2-diphenyl-1-picrylhydrazyl (DPPH) radical scavenging activity [20]. In addition, we proved that the stereochemistry of the 3-hydroxyl group of flavan-3-ol-3,5-di-O-gallate is important for inhibitory activity against HeLa S3 cell proliferation [20]. 


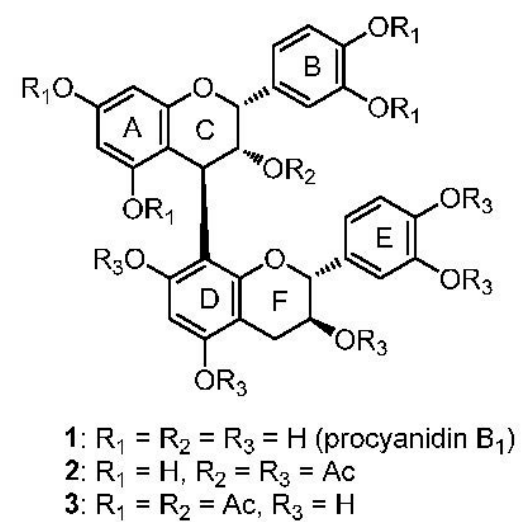

Figure 1. Structure of procyanidin B1 (1) and semi-acetylated analogues: lower-unit acetylated B1 (2) and upper-unit acetylated B1 (3).

Here, we describe further investigations. Synthetic studies of dimeric flavan-3-ols, (-)-epigallocatechin3-O-gallate (4), (-)-epigallocatechin (5), and (+)-catechin (6) as well as SAR studies were performed (Figure 2). In addition to the inhibitory activity assay against HeLa S3 cell, antimicrobial activity against Saccharomyces cerevisiae is also demonstrated. Oligomeric flavan-3-ols consisting of 4, 5 and 6 are isolated from fermented foods such as beer, wine, etc. Flavan-3-ols and proanthocyanidins are known as antimicrobial active agents against various microorganisms, including yeast [21]. Although numerous studies about the biologically effect on yeast of plant extracts which are mixtures of various polyphenol compounds have been reported [22,23], there is little information allowing a detailed SAR study. Our results suggested that increases in the number of phenolic hydroxyl groups in the entire molecule correlate poorly with biological activities. In addition, we confirmed the importance of the upper-unit for the functionality of dimeric flavan-3-ols.<smiles>O=C(O[C@H]1Cc2c(O)cc(O)cc2O[C@H]1c1cc(O)c(O)c(O)c1)c1cc(O)c(O)c(O)c1</smiles><smiles>Oc1cc(O)c2c(c1)OC(c1cc(O)c(O)c(O)c1)C(O)C2</smiles><smiles>Oc1cc(O)c2c(c1)OC(O)C(c1ccc(O)c(O)c1)C2</smiles>

Figure 2. Structure of principal flavan-3-ols.

\section{Results and Discussion}

The synthesis targets are shown in Figure 3. We synthesized four dimeric compounds: $(-)$-epigallocatechin-[4,8]-(+)-catechin (7), (-)-epigallocatechin-[4,8]-(-)-epigallocatechin $(-)$-epigallocatechin-[4,8]-(-)-epigallocatechin-3-O-gallate $(9)$, and (+)-catechin-[4,8]-(-)-epigallocatechin (10) to determine which part is the most important for biological activities and if the total number of phenolic hydroxyl groups in the entire molecule correlates with biological properties. The synthesized compounds 7-10 are natural products that can be isolated from beverages, e.g., green tea [24] and beer [25], and are known as strongly bioactive polyphenols. 

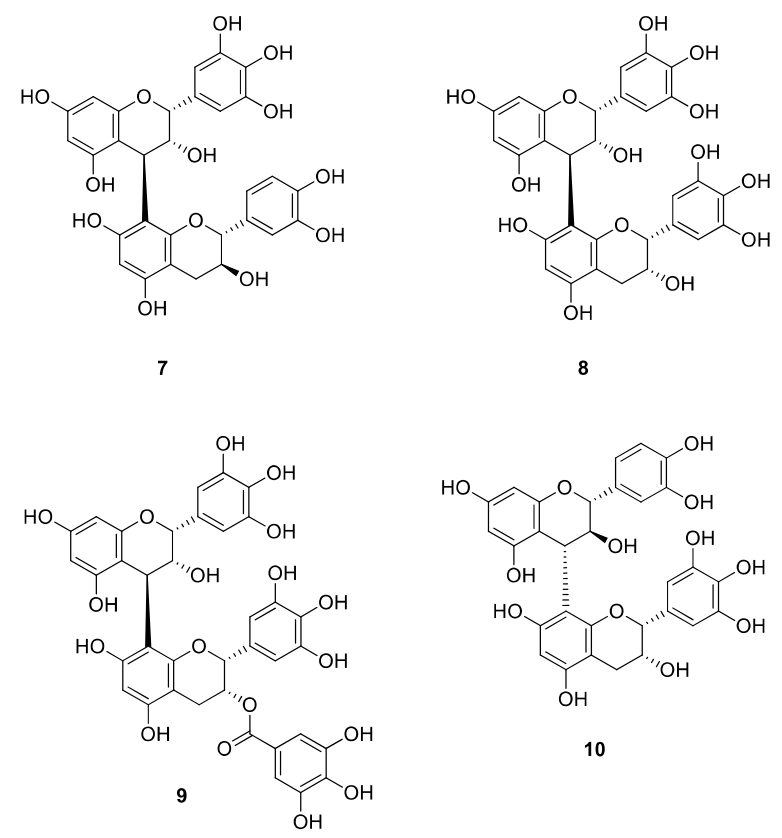

10

Figure 3. Synthesized dimeric flavan-3-ols.

Compounds 7-9 were synthesized using an electrophile $\mathbf{1 3}$ derived from commercially available (-)-epigallocatechin-3-O-gallate (EGCG: 4), as shown in Scheme 1. Eight phenolic hydroxyl groups of 4 were protected with benzyl groups. This reaction proceeded smoothly and afforded octa- $O$-benzylated EGCG (11) in 66\% yield. The galloyl ester moiety of 11 was removed by alkaline hydrolysis to give $\mathbf{1 2}$ in quantitative yield. Compound 12 was converted to electrophile $\mathbf{1 3}$ by oxidative modification at the C4 position with DDQ and 2-ethoxyethanol [26].
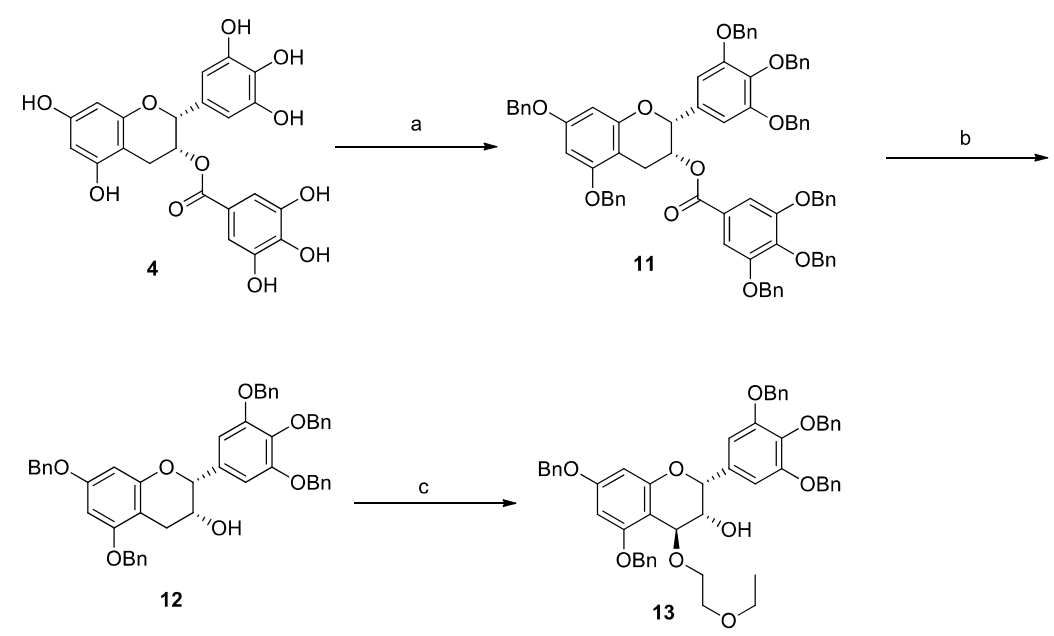

Scheme 1. Synthesis of EGCG electrophile 13. Reagents and conditions: (a) $\mathrm{BnBr}, \mathrm{K}_{2} \mathrm{CO}_{3}$, DMF, 66\%; (b) $\mathrm{K}_{2} \mathrm{CO}_{3}, \mathrm{CH}_{2} \mathrm{Cl}_{2}-\mathrm{MeOH}$, quant.; (c) 2-ethoxyethanol, DDQ, $\mathrm{CH}_{2} \mathrm{Cl}_{2}, 64 \%$.

The electrophile 13 was condensed with 14, 12, and 11 and gave dimeric compounds 15, 16, and 17 in $56 \%, 57 \%$, and $40 \%$ yields, respectively (Scheme 2). In those condensation reactions, only 3,4-trans products were obtained stereoselectively without 3-O-modification of electrophile 13. Following HPLC purification, removal of benzyl groups by hydrogenation with $\mathrm{Pd}(\mathrm{OH})_{2} / \mathrm{C}$ under $\mathrm{H}_{2}$ atmosphere afforded $\mathbf{7}, \mathbf{8}$, and 9 as pure products in $23 \%, 31 \%$, and $21 \%$ yields, respectively. We expected that comparison 
between 7 and 8 would show the effect on biological activities induced by the difference in the number of hydroxyl groups on the lower-unit B-ring and that the galloyl modified 9 could demonstrate whether the galloyl moiety of the lower-unit is effective to improve activity.

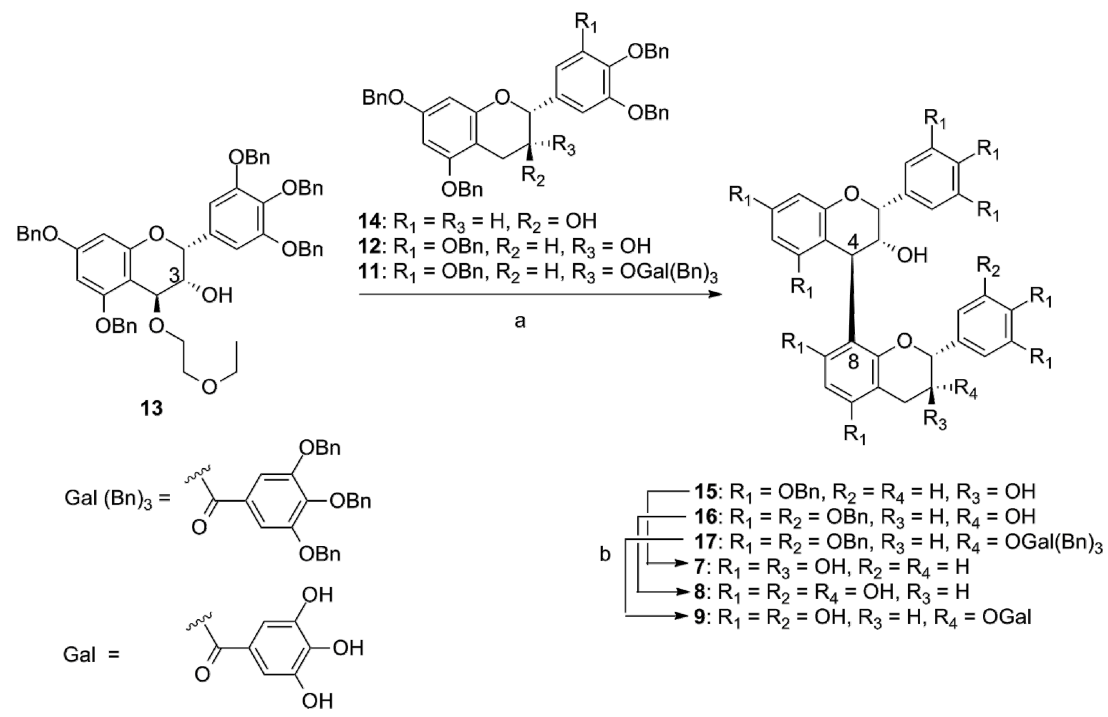

Scheme 2. Synthesis of 7-9. Reagents and conditions: (a) TMSOTf, $-20{ }^{\circ} \mathrm{C}, \mathrm{CH}_{2} \mathrm{Cl}_{2}$, 15: $56 \%, 16: 57 \%, 17: 40 \%$; (b) $\mathrm{Pd}(\mathrm{OH})_{2} / \mathrm{C}, \mathrm{H}_{2}, \mathrm{THF}-\mathrm{MeOH}-\mathrm{H}_{2} \mathrm{O}$ then HPLC purification, 7: $23 \%, 8: 31 \%, 9: 21 \%$.

Synthesis of $(+)$-catechin-[4,8]-(-)-epigallocatechin (10), a reference compound of 7, is shown in Scheme 3. The electrophile 18 [27] was condensed with a nucleophile $\mathbf{1 2}$ in the presence of TMSOTf as the Lewis acid at $-78{ }^{\circ} \mathrm{C}$ in $\mathrm{CH}_{2} \mathrm{Cl}_{2}$ and gave dimeric compound 19 in $84 \%$ yield. The acetyl group of 19 was removed by DIBAL-H, and deprotection of the benzyl groups by hydrogenation conditions and HPLC purification afforded compound 10, which had the same building unit as compound 7.

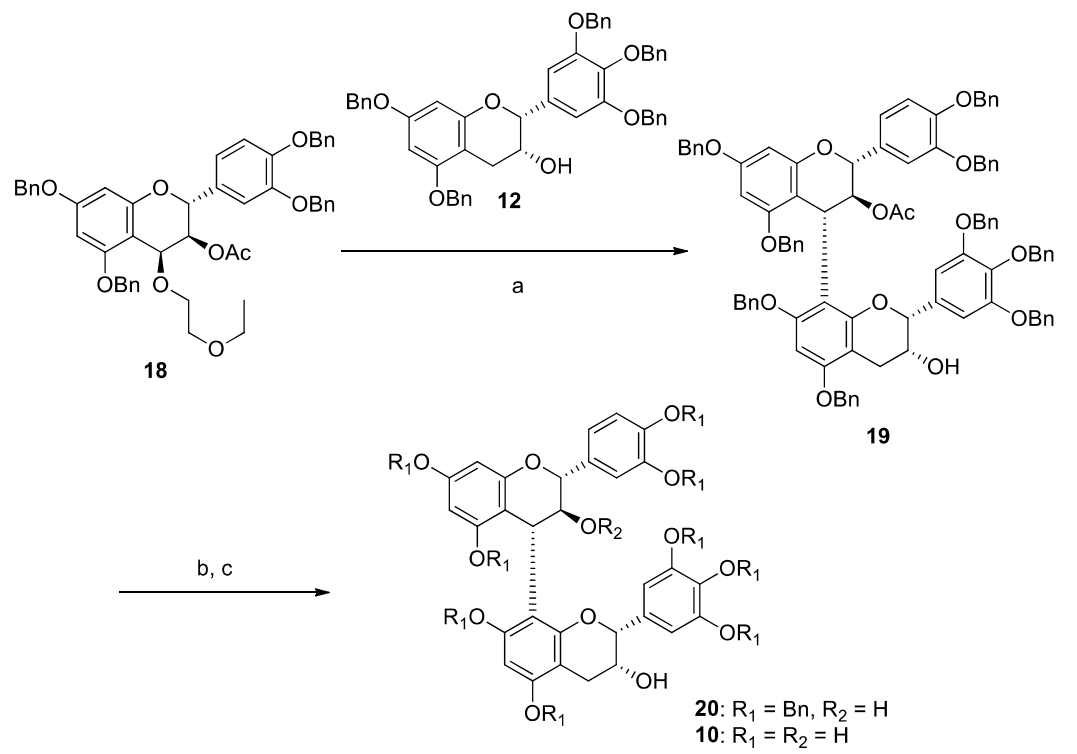

Scheme 3. Synthesis of 10. Reagents and conditions: (a) 12, TMSOTf, $\mathrm{CH}_{2} \mathrm{Cl}_{2},-78{ }^{\circ} \mathrm{C}$, $84 \%$; (b) DIBAL-H, $\mathrm{CH}_{2} \mathrm{Cl}_{2},-78^{\circ} \mathrm{C}$, quant.; (c) $\mathrm{Pd}(\mathrm{OH})_{2} / \mathrm{C}, \mathrm{H}_{2}$, THF-MeOH- $\mathrm{H}_{2} \mathrm{O}$ (20:1:1) then HPLC purification, $21 \%$. 


\subsection{DPPH Radical Scavenging Activity}

Polyphenol compounds are known as extremely strong antioxidants and radical scavengers. In previous studies, we investigated the DPPH radical scavenging activity of synthesized oligomeric flavan-3-ols and derivatives [15-18,20]. In Figure 4, DPPH radical scavenging activities of 1, 4, 7-10 at a final concentration of 10,5 , and $1 \mu \mathrm{M}$ are shown [28]. The $\mathrm{SC}_{50}$ values (the concentration of $50 \%$ scavenging activity) of these compounds were $6.0,3.3,4.7,3.7,2.9$, and $5.9 \mu \mathrm{M}$, respectively. These $\mathrm{SC}_{50}$ values suggested that the number of phenolic hydroxyl groups was no correlated with DPPH radical scavenging activity. Surprisingly, EGCG (4), non-oligomeric compound, was a more effective radical scavenger than the oligomeric compounds.

\subsection{Antimicrobial Activity against S. cerevisiae}

Antimicrobial activity against $S$. cerevisiae is shown in Figure 5. Upper-unit epigallocatechin compounds $\mathbf{7}$ and $\mathbf{8}$ exhibited strong inhibitory activity against $S$. cerevisiae proliferation. It should be noted that activity comparison between compound 7 and reference procyanidin B1 (1) revealed that the three hydroxyl groups on the B-ring in the upper-unit are very important. Contrary to our expectations, it is clear from the activity between $\mathbf{8}$ and $\mathbf{9}$ that the galloyl moiety at the lower-unit resulted in decreased activity. Surprisingly, compound 10, which had the same building unit (number of hydroxy groups) as compound 7 , showed no inhibitory activity of proliferation against $S$. cerevisiae. These data reveal that the existence of upper-unit hydroxyl groups in the dimeric structure is important for strong activities. Furthermore, microbial activity against $S$. cerevisiae showed no correlation to DPPH radical scavenger ability, which suggests that this antimicrobial activity is due to another mechanism.

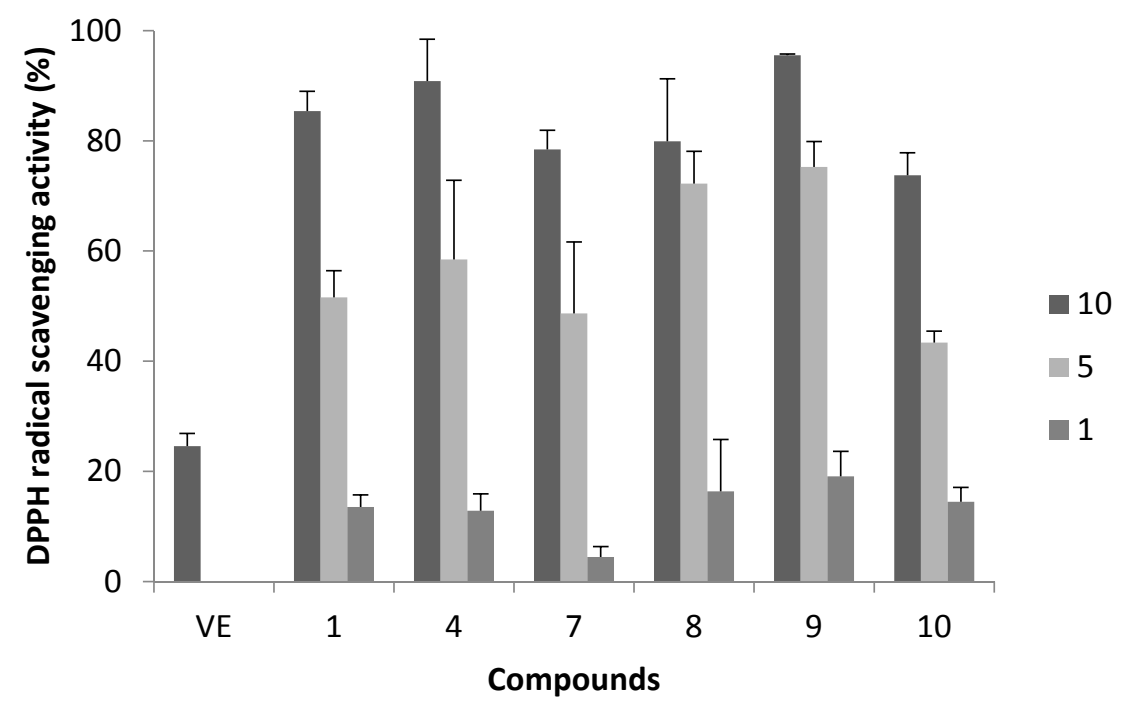

Figure 4. DPPH radical scavenging activity of synthesized compounds. $1 \mathrm{~mL}$ of $30 \mu \mathrm{M}$ of DPPH solution in EtOH was added to $1 \mu \mathrm{L}$ of sample solution in Dimethyl sulfoxide (DMSO) at final concentrations of 1,5 , and $10 \mu \mathrm{M}(n=6)$. Vitamin E was used as a control compound. Error bars represent standard deviation of the mean $(n=6)$. 


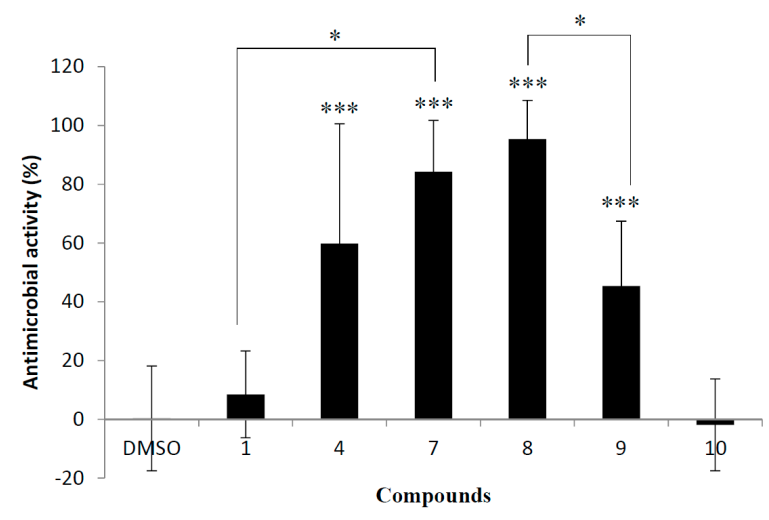

Figure 5. Antimicrobial activity of synthesized dimeric flavan-3-ols (1, 4, and 7-10) against S. cerevisiae. Comparison of antimicrobial activity (\%) at final concentration of $50 \mu \mathrm{M}$ after $20 \mathrm{~h}$ incubation. $200 \mu \mathrm{L}$ of culture medium of $S$. cerevisiae at O.D.600nm 0.25 was treated with $1 \mu \mathrm{L}$ of DMSO solution of $\mathbf{1 , 4}$, and 7-10 at final concentrations of $50 \mu \mathrm{M}$. DMSO was used as a negative control. Error bars represent standard deviation of the mean $(n=6)$. *** $p<0.001$ vs. DMSO-treated groups, asterisks indicate $* p<0.001$ in Student's $t$ test.

\subsection{Cervical Epithelioid Carcinoma Cell Line, HeLa S3 Proliferation Inhibitory Activity}

The inhibitory activities of the synthetic dimeric flavan-3-ols against HeLa S3 cell proliferation are shown in Figure 6. Similar to antimicrobial activity against $S$. cerevisiae, compound $\mathbf{1 0}$ showed low activity relative to other synthesized compounds 7-9. Compared to compound 10, the significance of the upper epigallocatechin unit of $\mathbf{7}$ is clear. Furthermore, the huge difference of activity between $\mathbf{1}$ and 7 indicates the importance of the third hydroxyl group on the B-ring. In addition, this activity was not enhanced by the introduction of a galloyl moiety to the lower-unit. Among the tested compounds, compound 7, 8 and 9 showed comparable inhibitory activity, which indicates that the structure of the lower-unit is not significant.

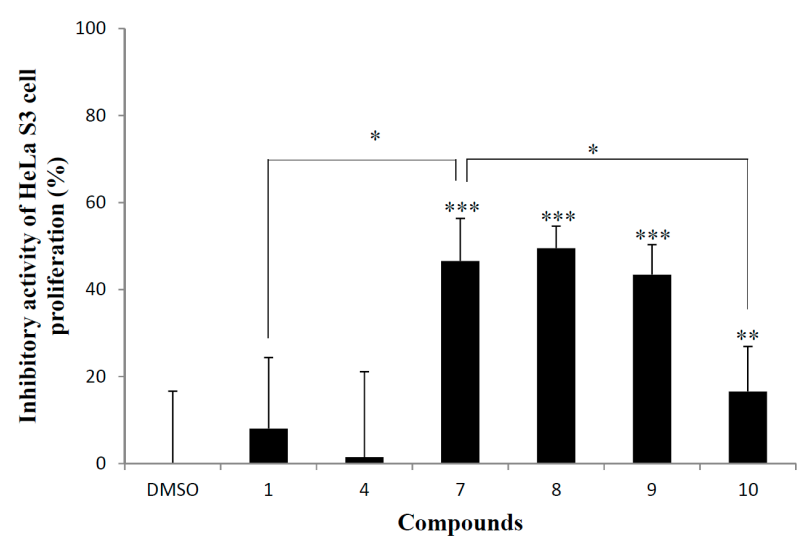

Figure 6. Inhibitory activity of synthetic dimeric flavan-3-ols against HeLa S3 cell proliferation. HeLa S3 was incubated with $1 \mu \mathrm{L}$ of DMSO solution of each compound (final $100 \mu \mathrm{M}$ ) for $48 \mathrm{~h}$. DMSO was used as a negative control. Error bars represent standard deviation of the mean $(n=14) .{ }^{* * *} p<0.001,{ }^{* *} p<0.005 v s$. DMSO-treated groups, asterisks indicate $* p<0.001$ in Student's $t$ test. 


\section{Experimental Section}

\subsection{General Information}

All commercially available chemicals for chemical synthesis were used without further purification. All reactions were performed under an argon atmosphere and monitored using thin-layer chromatography (TLC) with 0.25-mm pre-coated silica gel plates 60F254 (Art 5715, Merck KGaA, Darmstadt, Germany). An ATAGO (Minato, Japan) AP-300 spectrometer was used to measure optical rotation ${ }^{1} \mathrm{H}$ - and ${ }^{13} \mathrm{C}-\mathrm{NMR}$ spectra (400/100 MHz) were recorded on a DD2 NMR Spectrometer (Agilent, Santa Clara, CA, USA). A microTOFfocus mass spectrometer (Bruker Daltonics, Billerica, MA, USA) was used to acquire electrospray ionization (ESI) mass spectra. The human cervical adenocarcinoma cell line, HeLa-S3, and the normal human fibroblast, WI-38 cell line, was provided by the RIKEN BRC through the National Bio-Resource Project of the MEXT (Tsukuba, Japan). Synthesized compounds were dissolved in dimethyl sulfoxide (DMSO) and stored at $-25^{\circ} \mathrm{C}$. HPLC purification was carried out on an Ascentis ${ }^{\circledR}$ column (SUPELCO $^{\circledR}$ analytical, Sigma Aldrich Co., St. Louis, MO, USA; $25 \mathrm{~cm} \times 21.5 \mathrm{~mm}, 5 \mu \mathrm{m}$ ) using the solvents (A) $0.05 \% \mathrm{HCOOH}$ in $\mathrm{CH}_{3} \mathrm{CN}$ and (B) $0.05 \% \mathrm{HCOOH}$ and $10 \% \mathrm{CH}_{3} \mathrm{CN}$ in $\mathrm{H}_{2} \mathrm{O}$. Elution was done with a linear gradient $20 \%-100 \% \mathrm{~B}$ in $20 \mathrm{~min}$ (flow rate, $4.0 \mathrm{~mL} / \mathrm{min}$ ).

\subsection{Synthesis}

(2R,3R)-Octa-O-benzyl-(-)-epigallocatechin 3-O-gallate (11). To a solution of 4 (2.00 g, $4.36 \mathrm{mmol})$ in $\operatorname{DMF}(20.0 \mathrm{~mL})$ was added $\mathrm{K}_{2} \mathrm{CO}_{3}(6.02 \mathrm{~g}, 43.6 \mathrm{mmol})$ and $\mathrm{BnBr}(6.22 \mathrm{~mL}, 52.4 \mathrm{mmol})$ slowly at $0{ }^{\circ} \mathrm{C}$, and the mixture was stirred for $24 \mathrm{~h}$. The reaction mixture was quenched with $\mathrm{H}_{2} \mathrm{O}$ and extracted with EtOAc and the organic phase was washed with brine and dried with $\mathrm{MgSO}_{4}$. Filtration, concentration, and silica gel column chromatography ( $n$-hexane/EtOAc; 10:1-3:1, 40\% $\left.\mathrm{CHCl}_{3}\right)$ afforded $3.39 \mathrm{~g}$ of $\mathbf{1 1}(2.88 \mathrm{mmol}$, $66 \%)$ as a colorless amorphous powder: $[\alpha]_{D}^{24}-76.8\left(c 1.12, \mathrm{CHCl}_{3}\right) ;{ }^{1} \mathrm{H}-\mathrm{NMR}\left(\mathrm{CDCl}_{3}\right) 7.43-7.10(40 \mathrm{H}, \mathrm{m})$, $6.73(4 \mathrm{H}, \mathrm{s}), 6.40(1 \mathrm{H}, \mathrm{s}), 6.34(1 \mathrm{H}, \mathrm{s}), 5.66(1 \mathrm{H}, \mathrm{br} \mathrm{s}), 5.05-4.59(17 \mathrm{H}, \mathrm{m}), 3.14-3.08(2 \mathrm{H}, \mathrm{m})$; ${ }^{13} \mathrm{C}-\mathrm{NMR}$ $\left(\mathrm{CDCl}_{3}\right)$ 164.8, 158.9, 158.0, 155.6, 152.9, 152.4, 142.7, 138.4, 137.8, 137.5, 136.9, 136.8, 136.4, 133.2, 128.6-127.2 (×19), 125.0, 109.2, 106.7, 101.0, 94.7, 94.0, 78.0, 75.1, 75.0, 71.2, 71.1, 70.2, 70.0, 68.3, 26.2; ESILRMS (m/z) 1205 (35), 1203 (82), 1202 ([M + Na $\left.]^{+}, 100\right)$; ESIHRMS calcd. for $\mathrm{C}_{78} \mathrm{H}_{66} \mathrm{O}_{11} \mathrm{Na}$, 1201.4503; found 1201.4514 .

(2R,3R)-Penta-O-benzyl-(-)-epigallocatechin (12). To a solution of 11 (5.39 g, $4.57 \mathrm{mmol})$ in $\mathrm{CH}_{2} \mathrm{Cl}_{2} / \mathrm{MeOH}(1: 1)$ was added $\mathrm{K}_{2} \mathrm{CO}_{3}(5.05 \mathrm{~g}, 36.5 \mathrm{mmol})$ at $0{ }^{\circ} \mathrm{C}$, and the mixture was stirred for $30 \mathrm{~min}$. The reaction mixture was quenched with saturated $\mathrm{NH}_{4} \mathrm{Cl}$ solution and extracted with EtOAc. Drying, filtration, concentration, and silica gel column chromatography ( $n$-hexane/EtOAc; 10:1 2:1, 40\% $\mathrm{CHCl}_{3}$ ) afforded $3.46 \mathrm{~g}$ of 12 (4.57 mmol, quant.) as a colorless amorphous powder: [ $\alpha]_{D}^{24}-21.0\left(c 1.38, \mathrm{CHCl}_{3}\right)$; ${ }^{1} \mathrm{H}-\mathrm{NMR}\left(\mathrm{CDCl}_{3}\right) 7.45-7.20(25 \mathrm{H}, \mathrm{m}), 6.82(2 \mathrm{H}, \mathrm{s}), 6.29(2 \mathrm{H}, \mathrm{s}), 5.14(4 \mathrm{H}, \mathrm{s}), 5.07(2 \mathrm{H}, \mathrm{s}), 5.02-4.90$ $(5 \mathrm{H}, \mathrm{m}), 4.22(1 \mathrm{H}, \mathrm{br} \mathrm{s}), 3.01(1 \mathrm{H}, \mathrm{d}, J=13.6 \mathrm{~Hz}), 2.93(1 \mathrm{H}, \mathrm{dd}, J=3.6,13.6 \mathrm{~Hz}), 1.67(1 \mathrm{H}, \mathrm{br})$; ${ }^{13} \mathrm{C}-\mathrm{NMR}\left(\mathrm{CDCl}_{3}\right) 158.3,158.0,155.1,153.0,138.4,137.8,137.0,136.94,136.91,133.7,128.60,128.57$, 128.53, $128.5(\mathrm{C} \times 2), 128.2,128.0,127.91,127.90,127.8,127.6(\mathrm{C} \times 2), 127.5,127.2,106.2,201.0$, 94.7, 94.1, 78.6, 75.2, 71.3, 70.2, 70.0, 66.4, 28.1; ESILRMS (m/z) $781(14), 780(51), 779\left([\mathrm{M}+\mathrm{Na}]^{+}\right.$, 100), 758 (2.1), $757\left([\mathrm{M}+\mathrm{H}]^{+}, 3.7\right)$; ESIHRMS calcd. for $\mathrm{C}_{50} \mathrm{H}_{44} \mathrm{O}_{7} \mathrm{Na}, 779.2985$; found 779.2975. 
(2R,3R,4S)-Penta-O-benzyl-4-(2"-ethoxyethoxy)-(-)-epigallocatechin (13). To a solution of 12 (500 mg, $0.661 \mathrm{mmol})$ and ethoxyethanol $(0.639 \mathrm{~mL})$ in $\mathrm{CH}_{2} \mathrm{Cl}_{2}(35.0 \mathrm{~mL})$ was added slowly DDQ (1.49 equiv., $223 \mathrm{mg}, 0.982 \mathrm{mmol}$ ) at $0{ }^{\circ} \mathrm{C}$. After stirring for $5 \mathrm{~h}$ at RT, excess of 4-(dimethylamino)pyridine was added to the solution at $0{ }^{\circ} \mathrm{C}$ and the mixture was stirred for $10 \mathrm{~min}$. The resulting purple solid was removed by filtration and the filtrate was washed with water and brine, and dried $\left(\mathrm{MgSO}_{4}\right)$. Filtration, concentration and short silica gel column chromatography $\left(\mathrm{CHCl}_{3}\right)$ and silica gel column chromatography ( $n$-hexane/EtOAc; 10:1-3:1, 20\% $\mathrm{CHCl}_{3}$ ) afforded 13 (355 $\mathrm{mg}, 420 \mathrm{mmol}, 64 \%$ ) as a white foam: $[\alpha]_{D}^{28}-5.00\left(c \mathrm{c} 0.40, \mathrm{CHCl}_{3}\right) ;{ }^{1} \mathrm{H}-\mathrm{NMR}\left(\mathrm{CDCl}_{3}\right) 7.45-7.16(25 \mathrm{H}, \mathrm{m}), 6.85(2 \mathrm{H}, \mathrm{s}), 6.29(1 \mathrm{H}, \mathrm{s}), 6.28(1 \mathrm{H}, \mathrm{s})$, $5.17(1 \mathrm{H}, \mathrm{br} \mathrm{s}), 5.14(4 \mathrm{H}, \mathrm{s}), 5.06-5.02(6 \mathrm{H}, \mathrm{m}), 4.61(1 \mathrm{H}, \mathrm{br} \mathrm{s}), 4.03-4.01(1 \mathrm{H}, \mathrm{m}), 3.85-3.75(2 \mathrm{H}, \mathrm{m}), 3.51$ $(2 \mathrm{H}, \mathrm{t}, J=5.2 \mathrm{~Hz}), 3.42(2 \mathrm{H}, \mathrm{q}, J=6.8 \mathrm{~Hz}), 1.59-1.56(1 \mathrm{H}, \mathrm{m}), 1.17(3 \mathrm{H}, \mathrm{t}, J=6.8 \mathrm{~Hz}) ;{ }^{13} \mathrm{C}-\mathrm{NMR}\left(\mathrm{CDCl}_{3}\right)$ $160.6,159.8,156.1,153.1(\times 2), 138.4,131.8,136.9,136.72,136.70,128.6(\times 2), 128.5(\times 2), 128.2$, 128.0, 127.9, 127.8, 127.7, 127.6, 127.5, 106.4, 102.0, 94.4, 94.2, 75.2, 75.0, 71.4, 70.3, 70.1, 69.9, 68.9, 68.6, 66.5, 16.3; ESILRMS (m/z) 869 (19), $868(62), 867\left([\mathrm{M}+\mathrm{Na}]^{+}, 100\right), 846(3.7), 845\left([\mathrm{M}+\mathrm{H}]^{+}\right.$, 6.8); ESIHRMS calcd. for $\mathrm{C}_{54} \mathrm{H}_{52} \mathrm{O}_{9} \mathrm{Na}, 867.3509$; found 867.3515 .

$(2 R, 2 " R, 3 R, 3 " S, 4 R)$-[4,8]-2,3-cis-3,4-trans-Nona-O-benzyl-(-)-epigallocatechin-(+)-catechin (15). To a solution of $13(16.0 \mathrm{mg}, 18.9 \mu \mathrm{mol})$ and $14(55.0 \mathrm{mg}, 84.5 \mu \mathrm{mol})$ in $\mathrm{CH}_{2} \mathrm{Cl}_{2}(5.0 \mathrm{~mL})$ was added dropwise TMSOTf $\left(50.0 \mu \mathrm{L}, 25.0 \mu \mathrm{mol}, 0.5 \mathrm{M}\right.$ solution in $\left.\mathrm{CH}_{2} \mathrm{Cl}_{2}\right)$ at $-20{ }^{\circ} \mathrm{C}$. After stirring for $5 \mathrm{~min}$, the pale yellow reaction mixture was quenched with saturated $\mathrm{NaHCO}_{3}$. The mixture was extracted with $\mathrm{CHCl}_{3}$ and the organic phase was washed with water and brine, and dried $\left(\mathrm{MgSO}_{4}\right)$. Filtration, concentration, and preparative silica gel TLC purification (hexane/EtOAc, 2.5:1) afforded $15.0 \mathrm{mg}$ of $15(10.5 \mu \mathrm{mol}, 56 \%)$ as a colorless amorphous powder: $[\alpha]_{D}^{24}+30.0\left(c 0.10, \mathrm{CHCl}_{3}\right) ;{ }^{1} \mathrm{H}-\mathrm{NMR}\left(\mathrm{CDCl}_{3}\right.$, 0.77:0.23 mixture of rotational isomers) major isomer: $7.47-6.84(34.65 \mathrm{H}, \mathrm{m}), 6.80(0.77 \mathrm{H}, \mathrm{t}, J=8.0 \mathrm{~Hz})$, $6.73(0.77 \mathrm{H}, \mathrm{d}, J=1.4 \mathrm{~Hz}), 6.50(0.77 \mathrm{H}, \mathrm{dd}, J=1.4,8.1 \mathrm{~Hz}), 6.37(0.77 \mathrm{H}, \mathrm{s}), 6.04(0.77 \mathrm{H}, \mathrm{d}, J=2.2 \mathrm{~Hz})$, $5.57(0.77 \mathrm{H}, \mathrm{d}, J=2.2 \mathrm{~Hz}), 5.40(0.77 \mathrm{H}, \mathrm{s}), 5.18-4.91(13.86 \mathrm{H}, \mathrm{m}), 4.87(0.77 \mathrm{H}, \mathrm{d}, J=5.2 \mathrm{~Hz}), 4.64$ $(0.77 \mathrm{H}, \mathrm{d}, J=11.2 \mathrm{~Hz}), 4.54(0.77 \mathrm{H}, \mathrm{d}, J=11.3 \mathrm{~Hz}), 4.04(0.77 \mathrm{H}, \mathrm{m}), 3.76(0.77 \mathrm{H}, \mathrm{ddd}, J=6.8,9.2$, $9.6 \mathrm{~Hz}), 3.65(0.77 \mathrm{H}, \mathrm{d}, J=9.2 \mathrm{~Hz}), 3.26(0.77 \mathrm{H}, \mathrm{dd}, J=6.6,16.8 \mathrm{~Hz}), 2.60(0.77 \mathrm{H}, \mathrm{dd}, J=9.6,16.8 \mathrm{~Hz})$, $1.76(0.77 \mathrm{H}, \mathrm{br}, \mathrm{s}), 1.43(0.77 \mathrm{H}, \mathrm{br} \mathrm{s})$; minor isomer: $7.47-6.80(11.27 \mathrm{H}, \mathrm{m}), 6.24(0.23 \mathrm{H}, \mathrm{d}, J=2.2 \mathrm{~Hz})$, $6.21(0.23 \mathrm{H}, \mathrm{d}, J=2.3 \mathrm{~Hz}), 6.10(0.23 \mathrm{H}, \mathrm{d}, J=1.9 \mathrm{~Hz}), 5.31(0.23 \mathrm{H}, \mathrm{s}), 5.18-4.91(4.83 \mathrm{H}, \mathrm{m}), 4.42$ $(0.23 \mathrm{H}, \mathrm{d}, J=12.2 \mathrm{~Hz}), 3.61(0.23 \mathrm{H}, \mathrm{m}), 3.18(0.23 \mathrm{H}, \mathrm{dd}, J=5.3,16.2 \mathrm{~Hz}), 2.70(0.23 \mathrm{H}, \mathrm{dd}, J=9.5$, $16.3 \mathrm{~Hz}), 1.55(0.46 \mathrm{H}$, br s$) ;{ }^{13} \mathrm{C}-\mathrm{NMR}\left(\mathrm{CDCl}_{3}, 0.77: 0.23\right.$ mixture of rotational isomers $)$ major isomer: $158.2,157.0,156.0(\times 2), 155.1,154.6,153.1(\times 2), 149.3,148.8,138.3,138.0,137.4-137.0(\mathrm{C} \times 8)$, $134.9,130.3,128.7-126.8(\mathrm{C} \times 24), 120.6,114.0,112.1,111.3,106.3,104.4,104.2,93.6,93.1,91.6$, $81.7,75.3,72.4,71.4(\times 2), 71.3,70.7,70.3,70.0,69.6,69.2,68.7,35.6,29.1$; minor isomer: $158.4,157.8$ $(\times 2), 157.0,156.0,155.6,152.8(\times 2), 149.4,149.0,138.2,138.0,137.4-137.0(\mathrm{C} \times 8), 134.8,131.0$, 128.7-126.8 (C × 24), 120.2, 115.0, 114.6, 113.0, 106.8, 102.8, 102.3, 94.5, 93.4, 92.8, 81.6, 75.6, 71.5 $(\times 2), 71.3,71.2(\times 2), 71.0,70.2,68.4,68.2,35.7,29.7$; ESILRMS $(\mathrm{m} / \mathrm{z}) 1431(15), 1430(43), 1429$ (100), $1428\left([\mathrm{M}+\mathrm{Na}]^{+}, 91\right), 1408(11), 1407(21), 1406\left([\mathrm{M}+\mathrm{H}]^{+}, 22\right), 832(9.4), 831$ (15); ESIHRMS calcd. for $\mathrm{C}_{93} \mathrm{H}_{80} \mathrm{O}_{13} \mathrm{Na}, 1427.5497$; found 1427.5455 .

$\left(2 R, 2 " R, 3 R, 33^{\prime \prime} R, 4 R\right)$-[4,8]-2,3-cis-3,4-trans-Deca-O-benzyl-(-)-epigallocatechin-(-)-epigallocatechin (16). To a solution of $13(12.0 \mathrm{mg}, 14.2 \mu \mathrm{mol})$ and $\mathbf{1 2}(42.1 \mathrm{mg}, 55.7 \mu \mathrm{mol})$ in $\mathrm{CH}_{2} \mathrm{Cl}_{2}(5.0 \mathrm{~mL})$ was added 
dropwise TMSOTf $\left(40.0 \mu \mathrm{L}, 20.0 \mu \mathrm{mol}, 0.5 \mathrm{M}\right.$ solution in $\left.\mathrm{CH}_{2} \mathrm{Cl}_{2}\right)$ at $-20{ }^{\circ} \mathrm{C}$. After stirring for $5 \mathrm{~min}$, the pale yellow reaction mixture was quenched with saturated $\mathrm{NaHCO}_{3}$. The mixture was extracted with $\mathrm{CHCl}_{3}$ and the organic phase was washed with water and brine, and dried $\left(\mathrm{MgSO}_{4}\right)$. Filtration, concentration, and preparative silica gel TLC purification (hexane/EtOAc, 2:1) afforded $12.4 \mathrm{mg}$ of 16 $(8.09 \mu \mathrm{mol}, 57 \%)$ as a colorless amorphous powder: $[\alpha]_{D}^{23}-30.0\left(c 0.10, \mathrm{CHCl}_{3}\right)\left\{\right.$ lit. $[26][\alpha]_{D}^{23}+16.6$ (c 6.35, $\left.\left.\mathrm{CHCl}_{3}\right)\right\} ;{ }^{1} \mathrm{H}-\mathrm{NMR}\left(\mathrm{CDCl}_{3}, 0.75: 0.25\right.$ mixture of rotational isomers) major isomer: 7.46-6.80 $(37.5 \mathrm{H}, \mathrm{m}), 6.89(1.5 \mathrm{H}, \mathrm{s}), 6.40(1.5 \mathrm{H}, \mathrm{s}), 6.03(0.75 \mathrm{H}, \mathrm{d}, J=2.2 \mathrm{~Hz}), 5.71(0.75 \mathrm{H}, \mathrm{d}, J=2.2 \mathrm{~Hz}), 5.56$ $(0.75 \mathrm{H}, \mathrm{s}), 5.31-4.81(15 \mathrm{H}, \mathrm{m}), 4.68(0.75 \mathrm{H}, \mathrm{d}, J=11.2 \mathrm{~Hz}), 4.52(0.75 \mathrm{H}, \mathrm{d}, J=11.2 \mathrm{~Hz}), 4.08(0.75 \mathrm{H}$, br s), $3.98(0.75 \mathrm{H}, \mathrm{s}), 3.92-3.86(0.75 \mathrm{H}, \mathrm{m}), 3.01(0.75 \mathrm{H}, \mathrm{d}, J=17.9 \mathrm{~Hz}), 2.90(0.75 \mathrm{H}, \mathrm{dd}, J=4.8,17.9 \mathrm{~Hz})$, $1.77(0.75 \mathrm{H}, \mathrm{d}, J=5.3 \mathrm{~Hz}), 1.51(0.75 \mathrm{H}, \mathrm{d}, J=3.3 \mathrm{~Hz})$; minor isomer: $7.46-6.80(12.75 \mathrm{H}, \mathrm{m}), 6.68$ $(0.25 \mathrm{H}, \mathrm{d}, J=1.9 \mathrm{~Hz}), 6.37(0.5 \mathrm{H}, \mathrm{s}), 6.26(0.25 \mathrm{H}, \mathrm{d}, J=2.3 \mathrm{~Hz}), 6.21(0.25 \mathrm{H}, \mathrm{s}), 6.10(0.25 \mathrm{H}, \mathrm{d}, J=2.3 \mathrm{~Hz})$, $5.31-4.81(5 \mathrm{H}, \mathrm{m}), 4.63(0.25 \mathrm{H}, \mathrm{d}, J=12.0 \mathrm{~Hz}), 4.39(0.25 \mathrm{H}, \mathrm{d}, J=12.0 \mathrm{~Hz}), 4.09-3.85(0.5 \mathrm{H}, \mathrm{m})$, $3.60-3.70(0.25 \mathrm{H}, \mathrm{m}), 3.12-2.98(0.5 \mathrm{H}, \mathrm{m}), 1.69(0.25 \mathrm{H}, \mathrm{d}, J=6.0 \mathrm{~Hz}), 1.32(0.25 \mathrm{H}, \mathrm{d}, J=7.5 \mathrm{~Hz})$; ${ }^{13} \mathrm{C}-\mathrm{NMR}\left(\mathrm{CDCl}_{3}\right)$ 158.3, 158.0, 156.6, 156.0, 155.0, 154.4, 153.1, 152.6, 138.2, 138.0, 138.0, 137.6, $137.4,137.3,137.2,137.17,137.06,137.02,134.7,133.5,128.7,128.6,128.5,128.42,128.38,128.32$, $128.29,128.14,128.13,128.02,127.9,127.8,127.71,127.70,127.66,127.63,127.60,127.4,127.16$, $127.14,127.12,126.8,111.3,106.1,105.3,104.3,102.4,93.7,93.4,91.6,79.2,75.8,75.23,75.22,72.6$, $71.5,71.3,71.1,70.5,70.4,70.1,70.0,69.1,66.4,35.6,28.5$ (peaks of minor isomer were not identified); ESILRMS $(m / z) 1537(17), 1536(52), 1535\left([\mathrm{M}+\mathrm{Na}]^{+}, 100\right), 1534(8), 1512\left([\mathrm{M}+\mathrm{H}]^{+}, 0.8\right)$; ESIHRMS calcd. for $\mathrm{C}_{100} \mathrm{H}_{86} \mathrm{O}_{14} \mathrm{Na}, 1533.5915$; found 1533.5861 .

$\left(2 R, 2^{\prime \prime} R, 3 R, 3 " R, 4 R\right)$-[4,8]-2,3-cis-3,4-trans-Trideca-O-benzyl-(-)-epigallocatechin-(-)-epigallo-catechin3"-gallate (17). To a solution of $\mathbf{1 3}(13.0 \mathrm{mg}, 15.4 \mu \mathrm{mol})$ and $\mathbf{1 1}(81.3 \mathrm{mg}, 69.0 \mu \mathrm{mol})$ in $\mathrm{CH}_{2} \mathrm{Cl}_{2}(5.0 \mathrm{~mL})$ was added dropwise TMSOTf $\left(40.0 \mu \mathrm{L}, 20.0 \mu \mathrm{mol}, 0.5 \mu \mathrm{M}\right.$ solution in $\left.\mathrm{CH}_{2} \mathrm{Cl}_{2}\right)$ at $-20{ }^{\circ} \mathrm{C}$. After stirring for $5 \mathrm{~min}$, the pale yellow reaction mixture was quenched with saturated $\mathrm{NaHCO}_{3}$. The mixture was extracted with $\mathrm{CHCl}_{3}$ and the organic phase was washed with water and brine, and dried $\left(\mathrm{MgSO}_{4}\right)$. Filtration, concentration, and preparative silica gel TLC purification (hexane/EtOAc, 2:1) afforded $12.0 \mathrm{mg}$ of 17 $(6.14 \mu \mathrm{mol}, 40 \%)$ as a colorless amorphous powder: $[\alpha]_{D}^{25}-50.0\left(c 0.10, \mathrm{CHCl}_{3}\right) ;{ }^{1} \mathrm{H}-\mathrm{NMR}\left(\mathrm{CDCl}_{3}\right)$ $7.44-6.49(66.5 \mathrm{H}, \mathrm{m}), 6.94(1 \mathrm{H}, \mathrm{s}), 6.82(1 \mathrm{H}, \mathrm{s}), 6.79(1 \mathrm{H}, \mathrm{s}), 6.49(1 \mathrm{H}, \mathrm{s}), 6.44(0.5 \mathrm{H}, \mathrm{s}), 6.24(0.5 \mathrm{H}, \mathrm{s})$, $6.13(0.5 \mathrm{H}, \mathrm{br} \mathrm{s}), 6.12(0.5 \mathrm{H}, \mathrm{br} \mathrm{s}), 6.06(0.5 \mathrm{H}, \mathrm{br} \mathrm{s}), 5.82-5.78(0.5 \mathrm{H}, \mathrm{m}), 5.75(0.5 \mathrm{H}, \mathrm{br} \mathrm{s}), 5.69(0.5 \mathrm{H}, \mathrm{s})$, 5.43-5.38 (0.5H, m), 5.32-4.20 (25H, m), 4.26-4.22 (0.5H, m), 4.12-4.09 (0.5H, m), 3.36-3.30 (2H, m), $3.24(0.5 \mathrm{H}, \mathrm{dd}, J=5.8,18.3 \mathrm{~Hz}), 3.01(0.5 \mathrm{H}, \mathrm{d}, J=18.3 \mathrm{~Hz}), 1.85(0.5 \mathrm{H}, \mathrm{d}, J=6.4 \mathrm{~Hz}), 1.73(0.5 \mathrm{H}, \mathrm{d}$, $J=4.5 \mathrm{~Hz}) ;{ }^{13} \mathrm{C}-\mathrm{NMR}\left(\mathrm{CDCl}_{3}, 0.5: 0.5\right.$ mixture of rotational isomers $) 165.7,165.4,158.5,158.3,158.1$, $157.2,156.8,156.5,156.3,156.2,155.2,155.0,154.9,155.6,153.1,153.0,152.5,152.4,152.1,143.0$, $142.4,138.4,138.2,138.04,138.00,137.86,138.84,137.7,137.5,137.4,137.3,137.2,137.1,137.0$, 136.93, 136.91, 136.88, 136.82, 136.7 (×2), 136.6, 136.34, 136.28, 134.5, 134.4, 133.2, 132.7, 130.9, $128.73,128.69,128.60,128.54,128.47,128.41,128.39,128.36,128.34,128.29,128.28,128.26,128.25$, $128.20,128.18,128.14,128.10,128.08,128.07,128.05,128.03,128.00,127.96,127.93,127.88,127.85$, $127.78,127.75,127.72,127.69,127.65,127.62,127.59,127.54,127.46,127.44,127.42,127.39,127.32$, $127.18,127.17,125.1,124.7,111.9,111.3,109.4,109.0,106.8,106.3,105.7,104.7,104.2,103.1,101.9$, $94.8,94.1,93.7,93.4,92.4,92.0,78.6,76.0,75.6,75.3,75.2,75.1,75.0,74.0,72.7,72.4,71.5,71.4$, $71.33,71.26,71.1,70.9,70.73,70.66,70.1,70.0,69.9,69.8,69.3,69.1,68.2,67.9,37.1,35.5,29.7,26.7$ 
(22 peaks of benzyl groups were not observed); ESILRMS $(\mathrm{m} / \mathrm{z}) 1958(13), 1957(18), 1956\left([\mathrm{M}+\mathrm{Na}]^{+}\right.$, 13), 1351 (17), 1350 (25), 1235 (17), 1234 (24), 1187 (19), 1186 (32), 1177 (19), 1176 (26), 1143 (23), 1142 (40), 1099 (34), 1098 (58), 1011 (47), 1010 (100); ESIHRMS calcd. for $\mathrm{C}_{128} \mathrm{H}_{108} \mathrm{O}{ }_{18} \mathrm{Na}, 1955.7433$; found 1955.7427 .

$\left(2 R, 2^{\prime \prime} R, 3 R, 3 " S, 4 R\right)-[4,8]-2,3-$ cis-3,4-trans-(-)-Epigallocatechin-(+)-catechin (7). A solution of 15 $(110 \mathrm{mg}, 77.1 \mu \mathrm{mol})$ in $\mathrm{THF} / \mathrm{MeOH} / \mathrm{H}_{2} \mathrm{O}(20: 1: 1,22 \mathrm{~mL})$ was added to the mixture and hydrogenated over $20 \% \mathrm{Pd}(\mathrm{OH})_{2} / \mathrm{C}(5 \mathrm{mg})$ under $\mathrm{H}_{2}$ atmosphere for $12 \mathrm{~h}$ at RT. Filtration and concentration afforded a pale brown solid, which was purified with HPLC purification to give $10.4 \mathrm{mg}$ of pure 7 (17.5 $\mu \mathrm{mol}$, $23 \%)$ as a pale brown powder: $[\alpha]_{D}^{24}+67.3(c 0.033, \mathrm{MeOH})\left\{\right.$ lit. [26] $\left.[\alpha]_{D}^{22}+24.0(c 0.50, \mathrm{MeOH})\right\}$; ${ }^{1} \mathrm{H}-\mathrm{NMR}\left(\mathrm{CD}_{3} \mathrm{OD},-55^{\circ} \mathrm{C}\right) 6.88(1 \mathrm{H}, \mathrm{d}, J=8.6 \mathrm{~Hz}), 6.79(1 \mathrm{H}, \mathrm{s}), 6.67(1 \mathrm{H}, \mathrm{d}, J=8.2 \mathrm{~Hz}), 6.35(2 \mathrm{H}, \mathrm{s})$, $5.89(1 \mathrm{H}, \mathrm{d}, J=2.2 \mathrm{~Hz}), 5.87(1 \mathrm{H}, \mathrm{s}), 5.80(1 \mathrm{H}, \mathrm{s}), 5.03(1 \mathrm{H}, \mathrm{s}), 4.99(1 \mathrm{H}, \mathrm{d}, J=4.3 \mathrm{~Hz}), 4.64(1 \mathrm{H}, \mathrm{s})$, 4.22-4.14 (1H, m), $3.93(1 \mathrm{H}, \mathrm{s}), 2.63-2.42(2 \mathrm{H}, \mathrm{m}) ;{ }^{13} \mathrm{C}-\mathrm{NMR}\left(\mathrm{CD}_{3} \mathrm{OD},-55{ }^{\circ} \mathrm{C}\right) 158.5,157.7,156.4$, 155.7, 153.6, 146.3, 146.0, 145.6, 132.9, 132.1, 131.8, 119.0, 115.8, 113.4, 107.6, 106.3, 106.1, 102.3, 99.6, 96.4, 95.4, 94.6, 81.2, 76.8, 72.8, 67.9, 36.5, 26.0; ESILRMS (m/z) 619 (13), $618(48), 617$ $\left([\mathrm{M}+\mathrm{Na}]^{+}, 100\right), 597(11), 596(38), 595\left([\mathrm{M}+\mathrm{H}]^{+}, 81\right)$; ESIHRMS calcd. for $\mathrm{C}_{30} \mathrm{H}_{27} \mathrm{O}_{13}, 595.1452$; found 595.1441 .

(2R,2"R,3R,3"R,4R)-[4,8]-2,3-cis-3,4-trans-(-)-Epigallocatechin-(-)-epigallocatechin (8). A solution of $16(95.0 \mathrm{mg}, 61.9 \mu \mathrm{mol})$ in $\mathrm{THF} / \mathrm{MeOH} / \mathrm{H}_{2} \mathrm{O}(20: 1: 1,22 \mathrm{~mL})$ was added to the mixture and hydrogenated over $20 \% \mathrm{Pd}(\mathrm{OH})_{2} / \mathrm{C}(5 \mathrm{mg})$ under $\mathrm{H}_{2}$ atmosphere for $12 \mathrm{~h}$ at RT. Filtration and concentration afforded a pale brown solid, which was purified with HPLC purification to give $11.7 \mathrm{mg}$ of pure 8 (19.1 $\mu \mathrm{mol}$, $31 \%$ ) as a pale brown powder: $[\alpha]_{D}^{24}+10.3(c 0.29, \mathrm{MeOH})\left\{\right.$ lit. $\left.[26][\alpha]_{D}^{22}+24.0(c 0.50, \mathrm{MeOH})\right\}$; ${ }^{1} \mathrm{H}-\mathrm{NMR}\left(\mathrm{CD}_{3} \mathrm{OD},-55^{\circ} \mathrm{C}\right) 6.58(2 \mathrm{H}, \mathrm{s}), 6.30(2 \mathrm{H}, \mathrm{s}), 5.85(1 \mathrm{H}, \mathrm{s}), 5.55-5.40(2 \mathrm{H}, \mathrm{m}), 4.96(1 \mathrm{H}, \mathrm{s})$, $4.86(1 \mathrm{H}, \mathrm{s}), 4.59(1 \mathrm{H}, \mathrm{s}), 4.24(1 \mathrm{H}, \mathrm{br} \mathrm{s}), 3.78(1 \mathrm{H}, \mathrm{s}), 2.92(1 \mathrm{H}, \mathrm{d}, J=16.5 \mathrm{~Hz}), 2.79(1 \mathrm{H}, \mathrm{d}, J=16.5 \mathrm{~Hz})$; ${ }^{13} \mathrm{C}-\mathrm{NMR}\left(\mathrm{CD}_{3} \mathrm{OD},-55^{\circ} \mathrm{C}\right) 157.8,157.7,157.5,156.65,156.56,154.5,146.5,146.3,133.04,133.02$, 131.5, 131.1, 107.0, 106.1, 105.9, 102.1, 99.4, 96.5, 95.5, 95.2, 79.2, 76.8, 73.5, 66.9, 36.5, 30.2; ESILRMS $(\mathrm{m} / \mathrm{z}) 634(18), 633\left([\mathrm{M}+\mathrm{Na}]^{+}, 55\right), 613(7.8), 612(32), 611\left([\mathrm{M}+\mathrm{H}]^{+}, 100\right)$; ESIHRMS calcd. for $\mathrm{C}_{30} \mathrm{H}_{27} \mathrm{O}_{14}, 611.1401$; found 611.1356 .

(2R,2"R,3R,3"R,4R)-[4,8]-2,3-cis-3,4-trans-(-)-Epigallocatechin-(-)-epigallocatechin 3"-O-gallate (9). A solution of $17(150 \mathrm{mg}, 76.0 \mu \mathrm{mol})$ in $\mathrm{THF} / \mathrm{MeOH} / \mathrm{H}_{2} \mathrm{O}(20: 1: 1,22 \mathrm{~mL})$ was added to the mixture and hydrogenated over $20 \% \mathrm{Pd}(\mathrm{OH})_{2} / \mathrm{C}(5 \mathrm{mg})$ under $\mathrm{H}_{2}$ atmosphere for $12 \mathrm{~h}$ at $\mathrm{RT}$. Filtration and concentration afforded a pale brown solid, which was purified with HPLC purification to give $12.1 \mathrm{mg}$ of pure $6(15.9 \mu \mathrm{mol}, 21 \%)$ as a pale brown powder: $[\alpha]_{D}^{24}-64.3(c 0.14, \mathrm{MeOH}) ;{ }^{1} \mathrm{H}-\mathrm{NMR}\left(\mathrm{CD}_{3} \mathrm{OD}\right.$, $\left.-55^{\circ} \mathrm{C}\right) 7.00(2 \mathrm{H}, \mathrm{s}), 6.60(2 \mathrm{H}, \mathrm{s}), 6.41(2 \mathrm{H}, \mathrm{s}), 6.00(1 \mathrm{H}, \mathrm{s}), 5.96(1 \mathrm{H}, \mathrm{s}), 5.88(1 \mathrm{H}, \mathrm{s}), 5.59(1 \mathrm{H}, \mathrm{br} \mathrm{s})$, $5.12(1 \mathrm{H}$, br s), $5.07(1 \mathrm{H}$, br s), $4.79(1 \mathrm{H}$, br s), $3.91(1 \mathrm{H}, \mathrm{br} \mathrm{s}), 3.04(1 \mathrm{H}, \mathrm{d}, J=15.8 \mathrm{~Hz}), 2.89(1 \mathrm{H}, \mathrm{d}$, $J=15.8 \mathrm{~Hz}) ;{ }^{13} \mathrm{C}-\mathrm{NMR}\left(\mathrm{CD}_{3} \mathrm{OD}\right) 167.6,158.2,157.8,157.7,156.5,155.8,154.4,146.4(\times 2), 146.0$, 139.6, 133.3, 133.1, 131.7, 130.5, 121.0, 109.9, 107.9, 106.2, 106.1, 102.2, 99.0, 96.6, 95.6, 95.2, 78.1, 77.0, 73.6, 69.3, 36.5, 26.8; ESILRMS ( $\mathrm{m} / \mathrm{z}) 787$ (7.5), $786(24), 785\left([\mathrm{M}+\mathrm{Na}]^{+}, 53\right), 765$ (13), 764 (44), $763\left([\mathrm{M}+\mathrm{H}]^{+}, 100\right)$; ESIHRMS calcd. for $\mathrm{C}_{37} \mathrm{H}_{31} \mathrm{O}_{18}, 763.1510$; found 763.1532 . 
(2R,2"R,3S,3"R,4S)-[4,8]-2,3-trans-3,4-trans-3-Acetoxy-nona-O-benzyl-(+)-catechin-(-)-epi-gallocatechin (19). To a solution of $18(281 \mathrm{mg}, 360 \mu \mathrm{mol})$ and $12(959 \mathrm{mg}, 1.44 \mathrm{mmol})$ in $\mathrm{CH}_{2} \mathrm{Cl}_{2}(30 \mathrm{~mL})$ was added dropwise TMSOTf $\left(432 \mu \mathrm{L}, 432 \mu \mathrm{mol}, 1.0 \mathrm{M}\right.$ solution in $\left.\mathrm{CH}_{2} \mathrm{Cl}_{2}\right)$ at $-78{ }^{\circ} \mathrm{C}$. After stirring for $5 \mathrm{~min}$, the pale yellow reaction mixture was quenched with saturated $\mathrm{NaHCO}_{3}$. The mixture was extracted with $\mathrm{CHCl}_{3}$ and the organic phase was washed with water and brine, and dried $\left(\mathrm{MgSO}_{4}\right)$. Filtration, concentration, and silica gel column chromatography ( $n$-hexane/EtOAc; 8:1-2:1, 40\% $\mathrm{CHCl}_{3}$ ) afforded $464 \mathrm{mg}$ of 12 (302 $\mu \mathrm{mol}, 84 \%)$ of as a colorless amorphous powder: $[\alpha]_{D}^{23}-26.7\left(c 0.6, \mathrm{CHCl}_{3}\right) ;{ }^{1} \mathrm{H}-\mathrm{NMR}\left(\mathrm{CDCl}_{3}\right.$, 0.83:0.13 mixture of rotational isomers) major isomer: 7.47-6.77 $(35.69 \mathrm{H}, \mathrm{m}), 6.91(0.83 \mathrm{H}, \mathrm{d}, J=1.8 \mathrm{~Hz})$, $6.73(1.66 \mathrm{H}, \mathrm{s}), 6.62(0.83 \mathrm{H}, \mathrm{dd}, J=1.8,8.0 \mathrm{~Hz}), 6.23(0.83 \mathrm{H}, \mathrm{d}, J=2.4 \mathrm{~Hz}), 6.22(0.83 \mathrm{H}, \mathrm{s}), 6.14$ $(0.83 \mathrm{H}, \mathrm{d}, J=2.4 \mathrm{H} \mathrm{Hz}), 5.82(0.83 \mathrm{H}, \mathrm{t}, J=9.6 \mathrm{~Hz}), 5.18-4.82(14.11 \mathrm{H}, \mathrm{m}), 4.68(0.83 \mathrm{H}, \mathrm{d}, J=9.6 \mathrm{~Hz})$, $4.61(0.83 \mathrm{H}, \mathrm{d}, J=10.2 \mathrm{~Hz}), 4.48(0.83 \mathrm{H}, \mathrm{d}, J=10.2 \mathrm{~Hz}), 3.98-3.92(0.83 \mathrm{H}, \mathrm{m}), 3.57(0.83 \mathrm{H}, \mathrm{s}), 2.82$ $(0.83 \mathrm{H}, \mathrm{d}, J=17.2 \mathrm{~Hz}), 2.55(0.83 \mathrm{H}, \mathrm{dd}, J=4.4,17.2 \mathrm{~Hz}), 1.60(2.49 \mathrm{H}, \mathrm{s}), 1.51-1.50(0.83 \mathrm{H}, \mathrm{m})$; minor isomer: $7.47-6.61(5.98 \mathrm{H}, \mathrm{m}), 6.62(0.26 \mathrm{H}, \mathrm{s}), 6.19(0.13 \mathrm{H}, \mathrm{d}, J=2.4 \mathrm{~Hz}), 6.12(0.13 \mathrm{H}, \mathrm{d}, J=2.4 \mathrm{~Hz})$, $6.06(0.13 \mathrm{H}, \mathrm{t}, J=2.4 \mathrm{~Hz}), 5.92(0.13 \mathrm{H}, \mathrm{s}), 5.18-4.47(2.99 \mathrm{H}, \mathrm{m}), 2.98-2.95(0.26 \mathrm{H}, \mathrm{m}), 1.50(0.39 \mathrm{H}, \mathrm{s})$, a proton of hydroxyl group was not identified; ${ }^{13} \mathrm{C}-\mathrm{NMR}\left(\mathrm{CDCl}_{3}\right)$ 169.1, 158.2, 157.8, 156.6, 156.2, $155.8,152.9,149.1,149.0,137.9,137.4,137.3,137.2,137.0,136.5,128.7,128.6,128.4,128.3,128.2$, $128.1,128.0,127.8,127.7,127.5,127.3,127.0,121.3,114.6,113.6,110.8,108.3,105.8,100.2,94.8$, $94.3,91.3,80.4,75.3,73.0,71.7,71.3,71.2,71.0,70.2,70.0,66.0,35.2,28.3,20.7$; ESILRMS $(\mathrm{m} / \mathrm{z})$; 1488 (42.8), 1487 (71.7), 1486 (67.2), 1472 (52.7), 1471([M + Na $\left.]^{+}, 100\right), 1470$ (94.3), 1449 (4.8), 1448 $\left([\mathrm{M}+\mathrm{H}]^{+}, 4.8\right)$; ESIHRMS calcd. for $\mathrm{C}_{95} \mathrm{H}_{83} \mathrm{O}_{14}, 1447.5783$; found 1447.5777.

$\left(2 R, 2^{\prime \prime} R, 3 S, 3 " R, 4 S\right)$-[4,8]-2,3-trans-3,4-trans-Nona-O-benzyl-(+)-catechin-(-)-epigallocatechin (20). To a solution of $19(184 \mathrm{mg}, 127 \mu \mathrm{mol})$ in $\mathrm{CH}_{2} \mathrm{Cl}_{2}(20 \mathrm{~mL})$ was added dropwise DIBAL-H $(1.31 \mathrm{~mL}$, $1.31 \mathrm{mmol}, 1.0 \mathrm{M}$ solution in hexane) at $-78^{\circ} \mathrm{C}$. After stirring for $30 \mathrm{~min}$ at $\mathrm{RT}$, the pale yellow reaction mixture was quenched with saturated Rochelle salt. The mixture was extracted with $\mathrm{CHCl}_{3}$ and the organic phase was washed with brine, and dried $\left(\mathrm{MgSO}_{4}\right)$. Filtration, concentration, and preparative silica gel TLC purification (hexane/EtOAc, 2:1) afforded $176 \mathrm{mg}$ of $\mathbf{2 0}(125 \mu \mathrm{mol}, 99 \%)$ as a colorless amorphous powder: $[\alpha]_{D}^{23}-70.0\left(\right.$ c 2.06, $\left.\mathrm{CHCl}_{3}\right)$; ${ }^{1} \mathrm{H}-\mathrm{NMR}\left(\mathrm{CDCl}_{3}\right) 7.50-6.60(50 \mathrm{H}, \mathrm{m}), 6.22(1 \mathrm{H}, \mathrm{s}), 6.20(1 \mathrm{H}, \mathrm{d}$, $J=2.8 \mathrm{~Hz}), 6.17(1 \mathrm{H}, \mathrm{d}, J=2.8 \mathrm{~Hz}), 5.18-4.45(20 \mathrm{H}, \mathrm{m}), 4.28(1 \mathrm{H}, \mathrm{t}, J=9.2 \mathrm{~Hz}), 3.91(1 \mathrm{H}, \mathrm{br} \mathrm{s}), 3.77$ $(1 \mathrm{H}, \mathrm{s}), 2.97(1 \mathrm{H}, \mathrm{d}, J=17.3 \mathrm{~Hz}), 2.57(1 \mathrm{H}, \mathrm{dd}, J=4.28,17.3 \mathrm{~Hz})$, a proton of hydroxyl group was not identified; ${ }^{13} \mathrm{C}-\mathrm{NMR}\left(\mathrm{CDCl}_{3}\right)$ 158.0, 157.8, 156.8, 156.1, 155.5, 153.3, $152.9(\times 2), 149.3,149.1,138.0$, 137.8, 137.4, 137.3, 137.2, $137.15(\times 2), 137.08(\times 2), 136.7,134.3,131.6,128.6-127.1$ (30C), 121.3, $114.8,113.3,111.9,108.8,105.6,100.5,94.9,94.2,91.4,82.3,75.2,73.2,71.3,71.14(\times 2), 71.06,70.23$, 70.16, 70.04, 69.98, 66.0, 36.9, 27.9; ESILRMS ( $\mathrm{m} / \mathrm{z})$; 1446 (30.0), 1445 (47.6), 1444 (47.3), 1430 (41.0), $1429\left([\mathrm{M}+\mathrm{Na}]^{+}, 77.4\right), 1428(73.5), 1407(12.3), 1406\left([\mathrm{M}+\mathrm{H}]^{+}, 16.8\right), 1405$ (13.4); ESIHRMS calcd. for $\mathrm{C}_{93} \mathrm{H}_{81} \mathrm{O}_{13}, 1405.5677$; found 1405.5672 .

$\left(2 R, 2^{\prime \prime} R, 3 S, 3 " R, 4 S\right)-[4,8]-2,3-$ trans-3,4-trans-(+)-Catechin-(-)-epigallocatechin (10). A solution of 20 (140 mg, $99.6 \mu \mathrm{mol})$ in $\mathrm{THF} / \mathrm{MeOH} / \mathrm{H}_{2} \mathrm{O}(20: 1: 1,22 \mathrm{~mL})$ was added to the mixture and hydrogenated over $20 \% \mathrm{Pd}(\mathrm{OH})_{2} / \mathrm{C}(5 \mathrm{mg})$ under $\mathrm{H}_{2}$ atmosphere for $12 \mathrm{~h}$ at RT. Filtration and concentration afforded a pale brown solid, which was purified with HPLC purification to give $12.6 \mathrm{mg}$ of pure $\mathbf{1 0}(21.2 \mu \mathrm{mol}$, $21 \%)$ as a pale brown powder: $[\alpha]_{D}^{23}-138(c 0.116$, acetone $)\left\{\right.$ lit. $[29][\alpha]_{D}^{17}-168.9(c=1.0$, acetone $\left.)\right\}$; 
${ }^{1} \mathrm{H}-\mathrm{NMR}$ (CD $\mathrm{CDD}_{3} \mathrm{O}$ 0.91:0.09 mixture of rotational isomers) major isomer: $7.04(0.91 \mathrm{H}, \mathrm{d}, J=1.7 \mathrm{~Hz})$, $6.90(0.91 \mathrm{H}, \mathrm{dd}, J=1.7,8.1 \mathrm{~Hz}), 6.85(0.91 \mathrm{H}, \mathrm{d}, J=8.2 \mathrm{~Hz}), 6.73(1.82 \mathrm{H}, \mathrm{s}), 6.08(0.91 \mathrm{H}, \mathrm{s}), 5.88$ $(1.82 \mathrm{H}, \mathrm{s}), 4.92(0.91 \mathrm{H}, \mathrm{br} \mathrm{s}), 4.71(0.91 \mathrm{H}, \mathrm{d}, J=7.7 \mathrm{~Hz}), 4.61(0.91 \mathrm{H}, \mathrm{dd}, J=7.7,10.6 \mathrm{~Hz}), 4.46(0.91 \mathrm{H}$, d, $J=10.6 \mathrm{~Hz}), 4.31-4.27(0.91 \mathrm{H}, \mathrm{m}), 2.93(0.91 \mathrm{H}, \mathrm{dd}, J=4.1,21.0 \mathrm{~Hz}), 2.85(0.91 \mathrm{H}, \mathrm{d}, J=16.5 \mathrm{~Hz})$; minor isomer: $6.79(0.09 \mathrm{H}, \mathrm{d}, J=2.0 \mathrm{~Hz}), 6.70(0.09 \mathrm{H}, \mathrm{d}, J=8.7 \mathrm{~Hz}), 6.59(0.18 \mathrm{H}, \mathrm{s}), 6.49(0.09 \mathrm{H}$, dd, $J=1.8,8.4 \mathrm{~Hz}), 4.35(0.09 \mathrm{H}, \mathrm{d}, J=4.7 \mathrm{~Hz}), 4.25(0.09 \mathrm{H}, \mathrm{d}, J=6.6 \mathrm{~Hz}), 2.75-2.69(0.18 \mathrm{H}, \mathrm{m})$, a proton of hydroxyl group was not identified; ${ }^{13} \mathrm{C}$-NMR $\left(\mathrm{CDCl}_{3}\right)$ 177.5, 176.2, 175.0, 174.5, 173.9, 165.4, 165.0, 164.6, 152.0, 151.4, 150.6, 139.9, 135.3, 135.0, 126.9, 125.7, 118.3, 116.6, 116.5, 115.3, 102.5, 98.80, 92.52, 86.06, 57.35, 19.29; ESILRMS (m/z); 634 (7.8), 633 (23), 619 (10), $618(42), 617$ ([M + Na $]^{+}$, 100), $595\left([\mathrm{M}+\mathrm{H}]^{+}, 3.1\right)$; ESIHRMS calcd. for $\mathrm{C}_{30} \mathrm{H}_{27} \mathrm{O}_{13}, 595.1452$; found 595.1446.

\subsection{DPPH Radical Scavenging Activity}

DPPH radical scavenging activity was measured with general procedure [28]. A solution of DPPH radical in EtOH $(30 \mu \mathrm{M}, 1.0 \mathrm{~mL})$ was added to $1 \mu \mathrm{L}$ of the synthesized each compound in DMSO, and incubated at $30^{\circ} \mathrm{C}$ for $30 \mathrm{~min}(n=6)$. The scavenging activity was estimated with a microplate reader (Filter Max F5 multi-mode microplate reader; Molecular Devices, Downingtown, PA, USA) to measure the OD at $515 \mathrm{~nm}$. Negative controls, the samples that $1 \mu \mathrm{L}$ of DMSO added to the $1.0 \mathrm{~mL}$ of EtOH were prepared at the same time. And the absorbance values converted into the percentage radical scavenging activity as follows: [(absorbance of the control - absorbance of the sample)/absorbance of the control] $\times 100$. VE (vitamin E) was used as the standard sample.

\subsection{Antimicrobial Activity against S. cerevisiae}

Overnight culture of $S$. cerevisiae was diluted to $\mathrm{OD}=0.25$ with culture medium, and $200 \mu \mathrm{L}$ of aliquot was transferred to each well in a 96-well plate. Then $1 \mu \mathrm{L}$ of the DMSO solution of compound was added in each well to a final concentration of $50 \mu \mathrm{M}$, and the growth of the $S$. cerevisiae at $27^{\circ} \mathrm{C}$ with constant shaking was monitored by measuring absorbance at $600 \mathrm{~nm}$ every $15 \mathrm{~min}$ using an incubation reader, HiTS (Scinics, Itabashi, Japan). The results were obtained as growth curves as well as raw data. DMSO was used as negative controls. As negative controls, medium alone well and DMSO added to the well were prepared at the same time.

\subsection{Inhibitory Activity of HeLa S3 Cell Proliferation}

$10^{4}$ cells per well with $100 \mu \mathrm{L}$ of medium in a $37{ }^{\circ} \mathrm{C}$ incubator equilibrated with a $5 \% \mathrm{CO}_{2}: 95 \%$ humidified air atmosphere. D-MEM (Dulbecco's Modified Eagle’s Medium; Gibco ${ }^{\circledR}$ (Life Technologies, Grand Island, NY, USA) supplemented with 5\% fetal calf serum and 1\% Pen-Strep; Invitrogen ${ }^{\mathrm{TM}}$ (Life Technologies). After $24 \mathrm{~h}$ of incubation, $1 \mu \mathrm{L}$ of synthesized six compounds in DMSO were added (final $100 \mu \mathrm{M}$ ) and incubated for $48 \mathrm{~h}$. As negative controls, medium alone well and DMSO added to the well were prepared at the same time. After the medium was removed and the cell was washed with PBS, $90 \mu \mathrm{L}$ of new medium and $10 \mu \mathrm{L}$ of the MTT solution (3-(4,5-dimethylthiazol-2-yl)-2,5-diphenyltetrazolium bromide, $5 \mathrm{mg} / \mathrm{mL}$ ) was added to each well and incubated at $37^{\circ} \mathrm{C}$ for $2.5 \mathrm{~h}$. After incubation the reaction medium was removed and $100 \mu \mathrm{L}$ of DMSO was added to each well and mix thoroughly with the pipette. 
Following which, viable cells were assessed using a microplate reader (Filter Max F5 multi-mode microplate reader; Molecular Devices) to measure the OD at $570 \mathrm{~nm}$.

\section{Conclusions}

In conclusion, we have synthesized four dimeric flavan-3-ol derivatives to clarify the importance of the upper-unit for biological activities. Our results support the assumption that the hydroxyl groups on the B-ring of the upper-unit are essential for the antimicrobial activity against $S$. cerevisiae and HeLa S3 cell proliferation inhibitory activity. Furthermore the correlation of antimicrobial activity against S. cerevisiae, proliferation inhibitory activity on HeLa S3 cells and of 2,2-diphenyl-1-picrylhydrazyl radical scavenging activity with the number of phenolic hydroxyl groups was low. Further synthesis and biological works to explain these mechanisms are now underway, since much more research using various analogs is needed to completely understand the SAR of these compounds.

\section{Acknowledgments}

This work was supported by BRAIN: Program for Promotion of Basic and Applied Research for Innovations in Bio-oriented Industry (A. Saito), Technology Research Promotion Program for Agriculture, Forestry, Fisheries, and Food Industry (A. Saito), the Tojuro Iijima Foundation for Food and Technology (A. Saito), the Kurata Memorial Hitachi Science and Technology Foundation (A. Saito), JSPS KAKENHI Grant Number 24590014 (Grants-in-Aid for Scientific Research (C), N. Nakajima).

\section{Author Contributions}

Y.H. and S.T. synthesized all compounds for biological assays; Y.A. and S.O. measured the inhibitory activity against HeLa S3 cells proliferation; M.T., S.D. and M.I. measured the antimicrobial activity; T.K. measured the DPPH scavenging activity; M.H. measured MS spectrometry; T.K., N.N. and A.S. supervised the study; and Y.H. and A.S. wrote the manuscript.

\section{Conflicts of Interest}

The authors declare no conflict of interest.

\section{References}

1. Harborne, J.B. The Flavonoids: Advances in Research from 1986; Chapman and Hall: London, UK, 1993.

2. Harborne, J.B.; Baxter, H. The Handbook of Natural Flavonoids; John Wiley \& Sons: New York, NY, USA, 1999.

3. Tuckmantel, W.; Kozikowski, A.P.; Romanczyk, L.J., Jr. Studies in polyphenol chemistry and bioactivity. 1. 1 reparation of building blocks from $(+)$-catechin. Procyanidin formation. Synthesis of the cancer cell growth inhibitor, 3-O-galloyl-(2R,3R)-epicatechin-4 $\beta, 8$-[3-O-galloyl-(2R,3R)epicatechin]. J. Am. Chem. Soc. 1999, 121, 12073-12081. 
4. Kozikowski, A.P.; Tuckmantel, W.; George, C. Studies in polyphenol chemistry and bioactivity. 2. Establishment of interflavan linkage regio- and stereochemistry by oxidative degradation of an $O$-alkylated derivative of procyanidin B2 to $(R)-(-)-2,4$-diphenylbutyric acid. J. Org. Chem. 2000, 65, 5371-5381.

5. Kozikowski, A.P.; Tuckmantel, W.; Boettcher, G.; Romanczyk, L.J., Jr. Studies in polyphenol chemistry and bioactivity. 4. Synthesis of trimeric, tetrameric, pentameric, and higher oligomeric epicatechin-derived procyanidins having all-4 $\beta, 8$-interflavan connectivity and their inhibition of cancer cell growth through cell cycle arrest. J. Org. Chem. 2003, 68, 1641-1658.

6. Ohmori, K.; Ushimaru, N.; Suzuki, K. Oligomeric catechins: An enabling synthetic strategy by orthogonal activation and C(8) protection. Proc. Natl. Acad. Sci. USA 2004, 101, 12002-12007.

7. Tarascou, I.; Barathieu, K.; Andre, Y.; Pianet, I.; Dufourc, E.; Fouquet, E. An improved synthesis of procyanidin dimers: Regio- and stereocontrol of the interflavan bond. Eur. J. Org. Chem. 2006, 23, 5367-5377.

8. Sharma, P.K.; Kolchinski, A.; Shea, H.A.; Nair, J.J.; Gou, Y.; Romanczyk, L.J., Jr.; Schmitz, H.H.

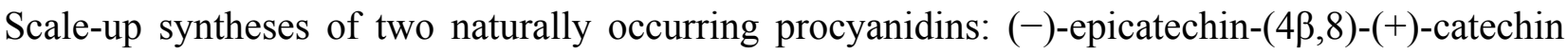
and (-)-epicatechin-3-O-galloyl-(4ß,8)-(-)-epicatechin-3-O-gallate. Org. Process. Res. Dev. 2007, $11,422-430$.

9. Mohri, Y.; Sagehashi, M.; Yamada, T.; Hattori, Y.; Morimura, K.; Kamo, T.; Hirota, M.; Makabe, H. An efficient synthesis of procyanidins. Rare earth metal Lewis acid catalyzed equimolar condensation of catechin and epicatechin. Tetrahedron Lett. 2007, 48, 5891-5894.

10. Oyama, K.; Kuwano, M.; Ito, M.; Yoshida, K.; Kondo, T. Synthesis of procyanidins by stepwise- and self-condensation using $(+)$-catechin and (-)-epicatechin as a key building monomer. Tetrahedron Lett. 2008, 49, 3176-3180.

11. Matthew, A.C.; Bonnet, S.L.; van der Westhuizen, J.H. Stereochemistry of sagittamide A: Prediction and confirmation. Org. Lett. 2008, 10, 3865-3868.

12. Mohri, Y.; Sagehashi, M.; Yamada, T.; Hattori, Y.; Morimura, Y.; Hamauzu, K.; Kamo, T.; Hirota, M.; Makabe, H. An efficient synthesis of procyanidins using equimolar condensation of catechin and/or epicatechin catalyzed by ytterbium triflate. Heterocycles 2009, 79, 549-563.

13. Watanabe, G.; Ohmori, K.; Suzuki, K. First regiocontrolled synthesis of procyanidin B6, a catechin dimer with rare connectivity: A halo-capping strategy for formation of 4,6-interflavan bonds. Chem. Commun. 2013, 49, 5210-5212.

14. Watanabe, G.; Ohmori, K.; Suzuki, K. A seco-catechin cyclization approach to 4-6-linked catechin dimers. Chem. Commun. 2014, 49, 14371-14373.

15. Saito, A.; Emoto, M.; Tanaka, A.; Doi, Y.; Shoji, K.; Mizushina, Y.; Ikawa, H.; Yoshida, H.; Matsuura, N.; Nakajima, N. Stereoselective synthesis of procyanidin B3-3-O-gallate and 3,3"-di- $O$-gallate, and their abilities as antioxidant and DNA polymerase inhibitor. Tetrahedron 2004, 60, 12043-12049.

16. Saito, A.; Mizushina, Y.; Ikawa, H.; Yoshida, H.; Doi, Y.; Tanaka, A.; Nakajima, N. Systematic synthesis of galloyl-substituted procyanidin B1 and B2, and their ability of DPPH radical scavenging activity and inhibitory activity of DNA polymerases. Bioorg. Med. Chem. 2005, 13, 2759-2771.

17. Sakuda, H.; Saito, A.; Mizushina, Y.; Ikawa, H.; Yoshida, H.; Tanaka, A.; Nakajima, N. Synthesis of galloyl-substituted procyanidin B4 series, and their DPPH radical scavenging activity and DNA polymerase inhibitory activity. Heterocycles 2006, 67, 175-188. 
18. Saito, A.; Mizushina, Y.; Tanaka, A.; Nakajima, N. Versatile synthesis of epicatechin series procyanidin oligomers, and their antioxidant and DNA polymerase inhibitory activity. Tetrahedron 2009, 65, 7422-7428.

19. Okamoto, S.; Ishihara, S.; Okamoto, T.; Doi, S.; Harui, K.; Higashino, Y.; Kawasaki, T.; Nakajima, N.; Saito, A. Inhibitory activity of synthesized acetylated procyanidin B1 analogs against HeLa S3 cells proliferation. Molecules 2014, 19, 1775-1785.

20. Mori, K.; Ayano, Y.; Hamada, Y.; Hojima, T.; Tanaka, R.; Higashino, Y.; Izuno, M.; Okamoto, T.; Kawasaki, T.; Hamada, M.; et al. Role of 2,3-cis structure of (-)-epicatechin-3,5-O-digallate in inhibition of HeLa S3 cell proliferation. Nat. Prod. Chem. Res. 2015, 3, doi:10.4172/2329-6836.1000172.

21. Sarnoski, P.J.; Boyer, R.R.; O'Keefe, S.F. Application of proanthocyanidins from peanut skins as a natural yeast inhibitory agent. J. Food Sci. 2012, 77, 242-249.

22. Li, J.; Zhao, H.; Huang, W. Mechanism of proanthocyanidins-induced alcoholic fermentation enhancement in Saccharomyces cerevisiae. J. Ind. Microbiol. Biotechnol. 2014, 41, 1793-1802.

23. Maeta, K.; Nomura, W.; Takatsume, Y.; Izawa S.; Inoue, Y. Green tea polyphenols function as prooxidants to activate oxidative-stress-responsive transcription factors in yeasts. Appl. Environ. Microbiol. 2007, 73, 572-580.

24. Oku, N.; Matsukawa, M.; Yamakawa, S.; Asai, T.; Yahara, S.; Hashimoto, F.; Akizawa, T. Inhibitory effect of green tea polyphenols on membrane-type 1 matrix metalloproteinase, MT1-MMP. Biol. Pharm. Bull. 2003, 26, 1235-1238.

25. Delcour, J.A.; Tuytens, G.M. Structure elucidation of three dimeric proanthocyanidins isolated from commercial Belgian pilsner beer. J. Inst. Brew. 1984, 90, 153-161.

26. Fujii, W.; Toda, K.; Matsumoto, K.; Kawaguchi, K.; Kawahara, S.; Hattori, Y.; Fujii, H.; Makabe, H. Syntheses of prodelphinidin B1, B2, and B4 and their antitumor activities against human PC-3 prostate cancer cell lines. Tetrahedron Lett. 2013, 54, 7188-7192.

27. Saito, A.; Nakajima, N.; Tanaka, A.; Ubukata, M. Synthetic studies of proanthocyanidins. Part 2: Stereoselective gram-scale synthesis of procyanidin-B3. Tetrahedron 2002, 58, 7829-7837.

28. Nanjo, F.; Goto, K.; Seto, R.; Suzuki, M.; Sakai, M.; Hara, Y. Scavenging effects of tea catechins and their derivatives on 1,1-diphenyl-2-picrylhydrazyl radical. Free Radic. Biol. Med. 1996, 21, 895-902.

29. Hashimoto, F.; Nonaka, G.; Nishioka, I. Tannins and related compounds. LXXVII. Novel chalcan-flavan dimers, assamicains A, B and C, and a new flavan-3-ol and proanthocyanidins from the fresh leaves of Camellia sinensis L. var. assamica KITAMURA. Chem. Pharm. Bull. 1989, 37, $77-85$.

Sample Availability: Samples of the compounds 1-3 and 7-10 are available from the authors.

(C) 2015 by the authors; licensee MDPI, Basel, Switzerland. This article is an open access article distributed under the terms and conditions of the Creative Commons Attribution license (http://creativecommons.org/licenses/by/4.0/). 